\title{
Miniaturized Tri-Band BPF using Asymmetric SIRs and DGS
}

\author{
Tasher Ali Sheikh ${ }^{*}$, Janmoni Borah ${ }^{1}$ and Sahadev Roy ${ }^{2}$ \\ 1, *Department of Computer science and Engineering \\ ${ }^{2}$ Department of Electronics and Communication Engineering \\ National Institute of Technology, Arunachal Pradesh, India-791112 \\ tasher372@gmail.com*,borah1989@gmail.com ${ }^{1}$,sahadevroy@gmail.com²
}

\begin{abstract}
In this paper, we proposed a tri-band microstrip Bandpass Filter (BPF) for the application of GSM (1.8GHz), WiMAX $(2.86 \mathrm{GHz})$ and $U W B(3.32-5.12 \mathrm{GHz})$. By integrating two narrow passbands filter with UWB filter; a tri-band response is achieved. The filter response performance is improved by introducing the asymmetric SIRs with Defected Ground structure (DGS). An appearance of transmission zeroes of the proposed structure guarantee the sharpness, the skirts of scattering parameters of triple-band Band pass filter (BPF). The proposed filter shows very low return loss of $-42.57 \mathrm{~dB}$, insertion loss of $-0.04 \mathrm{~dB}$, and compact which shows that the filter is more efficient.
\end{abstract}

Keywords: BPF, GSM, WiMAX, UWB, Impedance ratio, triple band, FWB, Asymmetric SIRs, DGS

\section{Introduction}

In RF communication systems, Filter is one of the most important elements. A high quality filter improves performance in communication system. BPF is an important component, used both at the transmitter and receiver in communication system. In RF communication system, BPF plays a key role in selecting the desired band in a specific bandwidth and attenuate unwanted signals. To select the desired frequency in commercial products like multi-service, the integration of multi-bands has become more significant. To design a multiband filter with multiple services are become an important issue and carried out in many ways [34-35]. Triple-Band transceivers have shown their abilities in modern multiband wireless communication systems [1,2]. The tri-band BPF have development a lot of attention over the past few years. In recent years, multiple service technology is widely and aggressively developed, especially in the RF wireless communication systems [3]. In traditional filter design, stepped-impedance resonator (SIR) is widely used to realize the multi-band responses because of compact in size with low insertion loss, proper coupling flexibility, high design freedom of selecting the length ratio $(\mathrm{u})$ and impedance ratio $(\mathrm{R})$ in the desired structure to achieve the desired Band [5-20]. In this paper, an integration of two narrow passband with the wide pass band has been presented in Figure 1 to achieve the tri-band response. An asymmetric SIRs and Ushape DGS is used to achieve the multi-bands response. The coupling structure of the propose tri-band filter is shown in Figure 2. The obtained tri-bands are uses in Global System for Mobile Communications (GSM) at $1.8 \mathrm{GHz}$ and Worldwide Interoperability for Microwave Access (WiMAX) at $2.86 \mathrm{GHz}$ and a wide pass band at Ultra Wide Band (UWB) from $3.32 \mathrm{GHz}$ to $5.12 \mathrm{GHz}$. The Centre frequency and Fractional Band width (FWB) $[34,3]$ can be calculate using (1) and (2) 
International Journal of Signal Processing, Image Processing and Pattern Recognition Vol. 8, No. 2 (2015)

$$
\begin{aligned}
& \omega_{0}=\sqrt{\omega_{1} \omega_{2}} \\
& F B W=\frac{\omega_{2}-\omega_{1}}{\omega_{0}}
\end{aligned}
$$

Where, $\boldsymbol{\omega}_{0}, \boldsymbol{\omega}_{1}$ and $\boldsymbol{\omega}_{2}$ are the centre frequency, lower cut-off -frequency and upper cut-off-frequency of the BPF. This proposes tri-band filter was design on Duriod 5870 substrate with thickness of $0.787 \mathrm{~mm}$, dielectric constant, $\varepsilon_{\mathrm{r}}$ of 2.23 and tangent loss, $\boldsymbol{\delta}$ of 0.0012 and the width of the microstrip are $0.2 \mathrm{~mm}$.

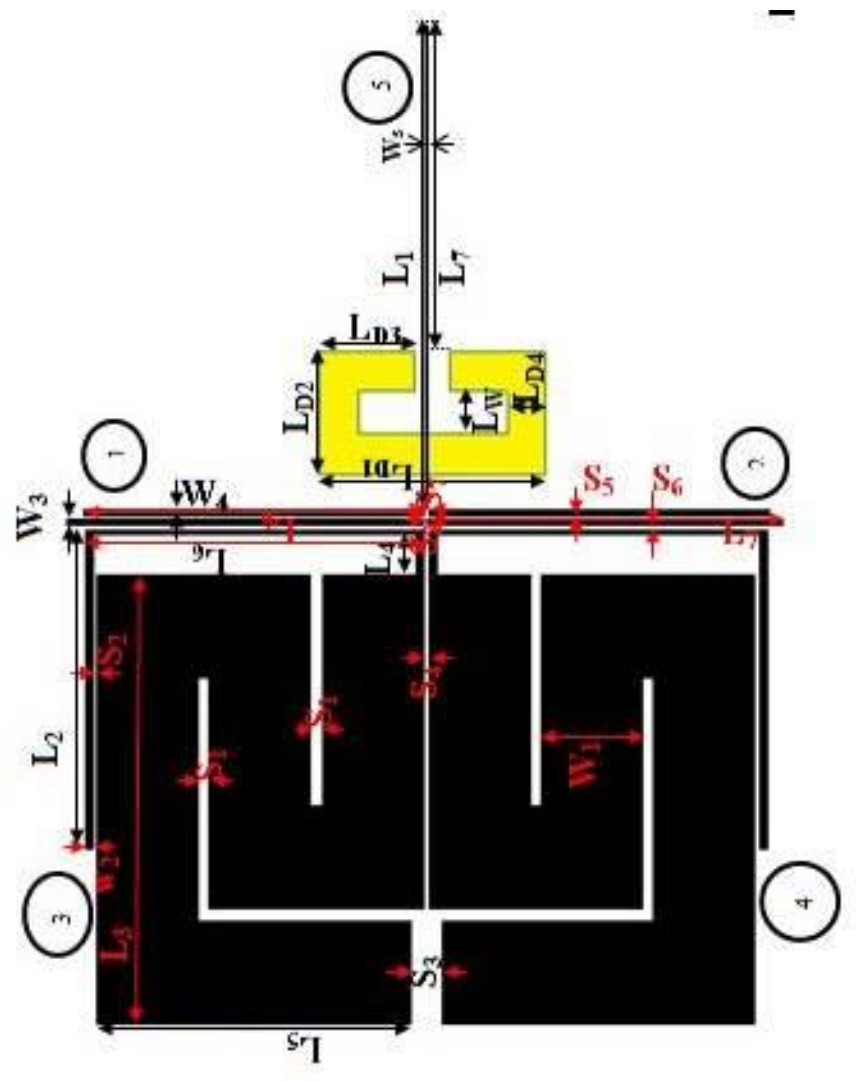

Figure 1. Design Layout of Tri-band Filter using Coupling Asymmetric SIR

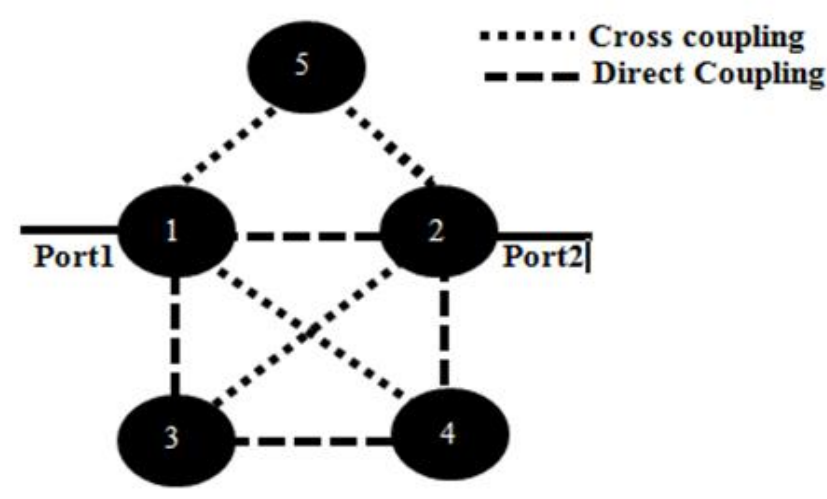

Figure 2. Coupling Structure of the Tri-band BPF 


\section{Design for GSM AND WiMAX}

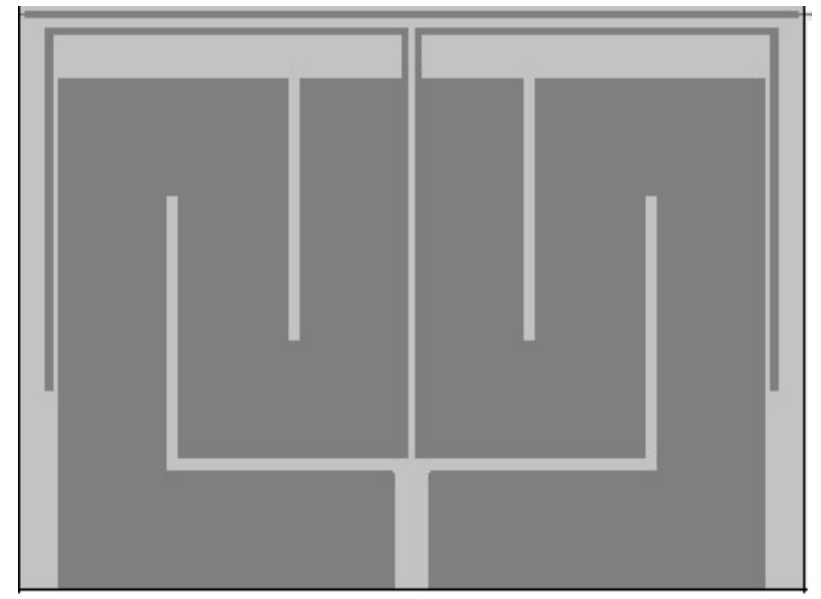

Figure 3. Design for GSM and WiMAX

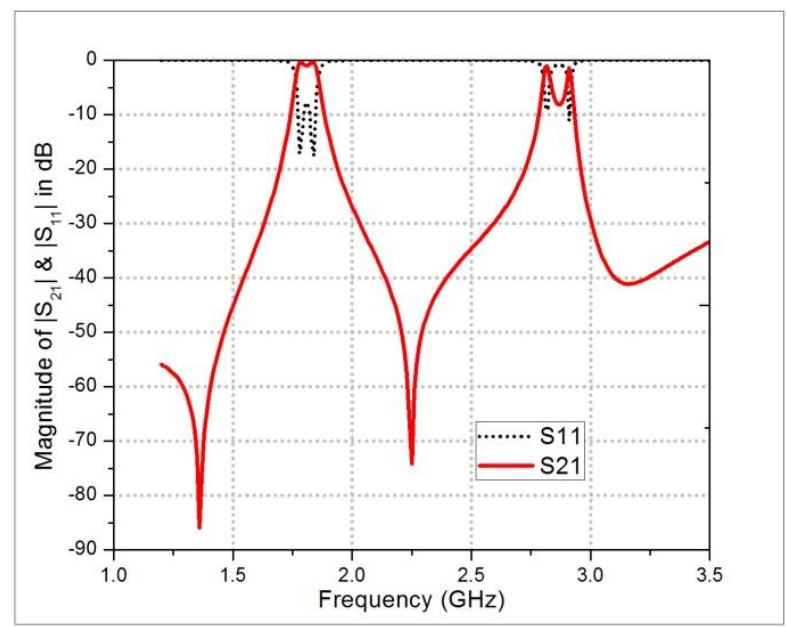

Figure 4. Magnitude of $S_{21}$ for GSM and WiMAX Response and their Phase Difference

The design specification of the dual-band filter is whose centre frequency are $\mathrm{f}_{1}=$ $1.8 \mathrm{GHz}$, and $\mathrm{f}_{2}=2.86 \mathrm{GHz}$, respectively. Based on the design response of Figure 3 the filter structure of the first two narrow pass bands, shown in Figure 4 achieve high impedance $\left(Z_{1}=79.21 \Omega\right)$ strip width of $0.2 \mathrm{~mm}$ and the low-impedance $\left(Z_{2}=45.78 \Omega\right)$ with a strip width of $3.85 \mathrm{~mm}$. The fractional bandwidths with different coupling spacing were calculated by Ansoft HFSS. The centre frequency for the first pass band $1.8 \mathrm{GHz}$ and the fractional Bandwidth (FBW) $5 \%$ and second pass band centre frequency is $2.86 \mathrm{GHz}$ and the FBW is $6.96 \%$ are obtain from the SIR 3 and SIR 4. To achieved good insertion loss $S_{21}$ is $-0.43 \mathrm{~dB}$ and $-0.95 \mathrm{~dB}$ and the returns loss is $S_{11}$ is $14.99 \mathrm{~dB}$ and $-10.92 \mathrm{~dB}$ for the $\mathrm{GSM}(1.8 \mathrm{GHz})$ and $\mathrm{WiMAX}(2.86 \mathrm{GHz})$ respectively . The coupling spacing can be as chosen $\mathrm{S}_{4}=0.2 \mathrm{~mm}$ to obtain the low insertion loss. 
Figure 3 shows the magnitude of $S_{21}$ of the two narrow band responses and the phase difference of transmission. It shows that the first passband and second passband are cantered at the desired frequencies of $1.8 \mathrm{GHz}$ and $2.86 \mathrm{GHz}$ respectively. The appearing of transmission zeros in both side of the passband is granted that sharpness of the scattering parameters of the design filter. The first transmission path is between the resonator 1 and resonator 2 , and the second transmission path in between resonator 3 and resonator 4. The coupling topologies formed by Input/output port of resonator 1, resonant 2.

\section{Design of UWB characteristics}

It is hard to obtain UWB response by using only two resonant modes of the SIRs. To generate UWB response the DGS is arranged under the resonator 5 symmetrically to avoid the design complexes and reduction of the losses. However, the DGS will affect the resonant modes of the asymmetric SIR, thus, the same length ratio $u$ and impedance ratio $R$, taken to obtained UWB response with center frequency 5.08GHz. It was known that DGS under the coupling resonators can be seen as a parallel LC resonator [21]; the capacitance and the inductance are calculate using (3) and (4)

$$
\begin{aligned}
& C=\frac{\omega_{c}}{Z_{0} g} \cdot \frac{1}{\omega_{0}^{2}-\omega_{c}^{2}} \\
& L=\frac{1}{4 \pi^{2} f_{0}^{2} C}
\end{aligned}
$$

Where $\omega_{c}, \omega_{o}$ is the cut-off frequency and Centre frequency of the low-pass filter, $\mathrm{Z}_{0}$ the Characteristic impedance of the input/output ports, and 'g' given by the element value of the prototype LPF. The operating frequency of DGS can be lowered while the reactance is increased by generally increasing the area or the number of DGSs. To design the third band we use a pair of asymmetric SIRs for the UWB response and DGS formed under the asymmetric SIRs of Resonators 5 to minimize the losses of the bandwidth, as shown in Figure 5. It is verify that by increasing the coupling length of the resonator 1 and resonator 2 significantly affect the UWB characteristic.

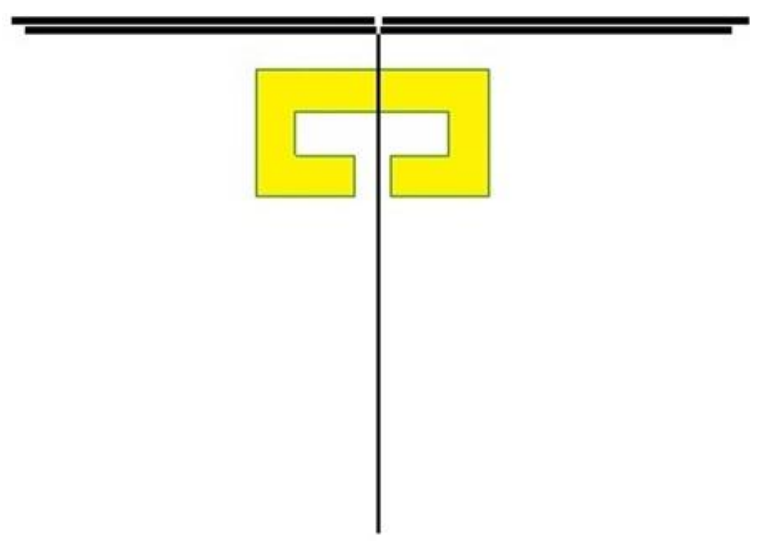

Figure 5. Design Model for UWB Response 


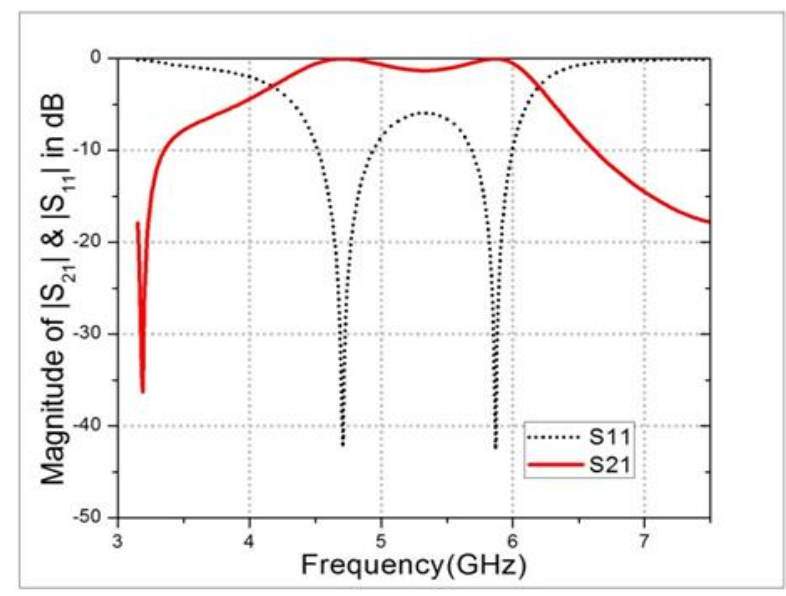

Figure 6. $S_{21}$ and $S_{11}$ Response and Phase different

When coupling line (L) are increased from $0 \mathrm{~mm}$ to $13.8 \mathrm{~mm}$ and with DGS, improves the insertion loss up to $-0.04 \mathrm{~dB}$. The UWB response with low insertion loss (S21) is $-0.04 \mathrm{~dB}$ and the FWB is $39.76 \%$ and the return loss $(\mathrm{S} 11)$ is $-42.57 \mathrm{~dB}$ that is shown in the Figure 5.

\section{Design for GSM, WiMAX and UWB and Responses}

The tri-band response and their group delay of the design BPF is depicted in Figure 7, Figure 8 and Figure 9. The centre frequencies of the three bands are $1.8 \mathrm{GHz}, 2.86 \mathrm{GHz}$ and 3.32-5.12GHz for GSM, WiMAX and UWB respectively. In this design the Bandwidth in UWB is improve. In single UWB designed structure its bandwidth was $4.17 \mathrm{GHz}-6.19 \mathrm{HGz}$, but after integrating the two narrow passband with UWB structure the spectrum is shifted to 3.32HGz-5.12GHz in tri-band design shown in Figure 7, which mean that it increases about $20 \%$ of Bandwidth than the other work in UWB. As we know that after the unlicensed the UWB band $(3.1 \mathrm{GHz}-10.6 \mathrm{GHz})$ operation from the FCC decision in February 2002 [22]. The UWB systems have many pleasing features such as transmitting higher data rates and requiring lower transmit power. The dimension taken for this design is shown in the Table 1 in above for obtaining the batter result.

Table 1. Design Parameters Dimension Table

\begin{tabular}{|c|c|c|c|c|c|c|c|c|c|}
\hline \multicolumn{6}{|c|}{$\begin{array}{l}\text { Dimension used for designing the GSM, } \\
\text { WiMAX and UWB response in mm. }\end{array}$} & \multicolumn{4}{|c|}{$\begin{array}{l}\begin{array}{l}\text { Dimension for DGS in } \\
\text { mm }\end{array} \\
\text {. }\end{array}$} \\
\hline \multicolumn{2}{|c|}{$\begin{array}{l}\text { Space between } \\
\text { two pec }\end{array}$} & \multicolumn{2}{|c|}{ Length } & \multicolumn{2}{|c|}{ width } & \multicolumn{2}{|c|}{ Length } & \multicolumn{2}{|c|}{ Width } \\
\hline $\mathrm{S}_{1}$ & 0.5 & $\mathrm{~L}_{1}$ & 18.2 & $\mathrm{~W}_{1}$ & 3.85 & $\mathrm{~L}_{\mathrm{D} 1}$ & 8.8 & $\mathrm{~L}_{\mathrm{W} 1}$ & 1.5 \\
\hline $\mathrm{S}_{2}$ & 0.25 & $\mathrm{~L}_{2}$ & 11.85 & $\mathrm{~W}_{2}$ & 0.2 & $\mathrm{~L}_{\mathrm{D} 2}$ & 4.6 & & \\
\hline $\mathrm{S}_{3}$ & 1.3 & $\mathrm{~L}_{3}$ & 16.9 & $\mathrm{~W}_{3}$ & 0.2 & $\mathrm{~L}_{\mathrm{D} 3}$ & 3.7 & & \\
\hline $\mathrm{S}_{4}$ & 0.3 & $\mathrm{~L}_{4}$ & 1.5 & $\mathrm{~W}_{4}$ & 0.2 & $\mathrm{~L}_{\mathrm{D} 4}$ & 1.6 & & \\
\hline $\mathrm{S}_{5}$ & 0.2 & $\mathrm{~L}_{5}$ & 12.05 & $\mathrm{~W}_{5}$ & 0.05 & & & & \\
\hline $\mathrm{S}_{6}$ & 0.2 & $\mathrm{~L}_{6}$ & 13 & & & & & & \\
\hline $\mathrm{S}_{7}$ & 0.05 & $\mathrm{~L}_{7}$ & 10.4 & & & & & & \\
\hline $\mathrm{S}_{8}$ & 0.2 & & & & & & & & \\
\hline & & & & & & & & & \\
\hline
\end{tabular}


International Journal of Signal Processing, Image Processing and Pattern Recognition Vol. 8, No. 2 (2015)

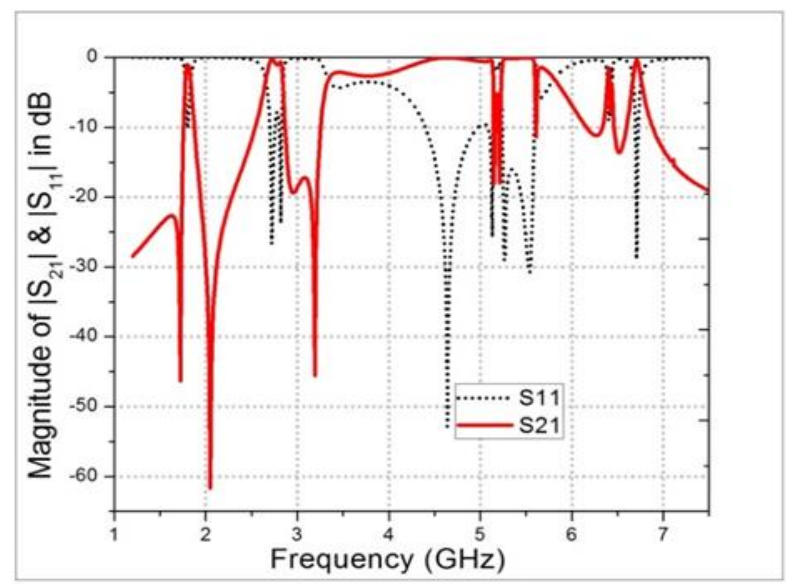

Figure 7. Magnitude Response of S21 and S11 for Tri-band

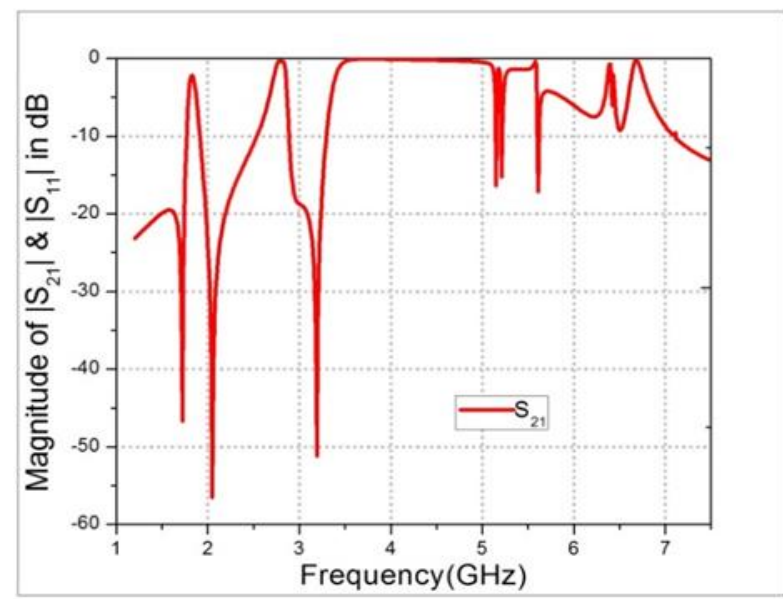

Figure 8. Magnitude Response of S21 for Tri-band

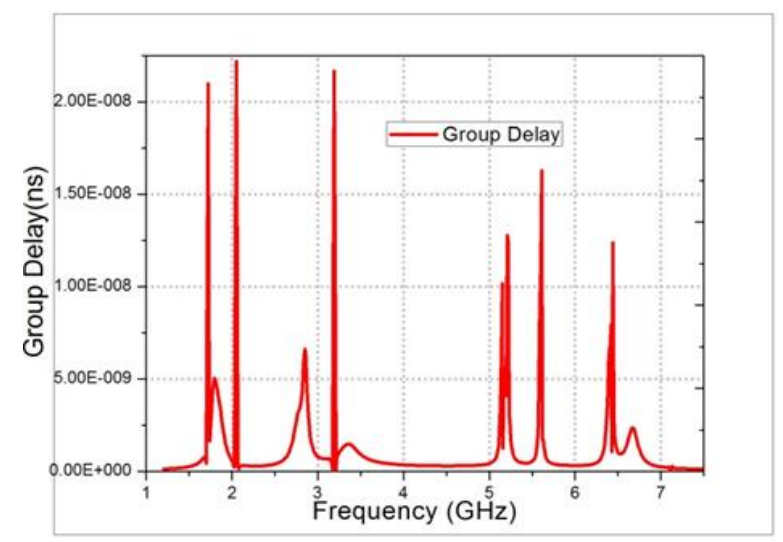

Figure 9. Group Delay (ns) 
Table 2. Comparison with Other Proposed Tri-band BPF

\begin{tabular}{|l|l|l|l|l|l|}
\hline $\begin{array}{l}\text { Comparison } \\
\text { of model }\end{array}$ & $\begin{array}{l}1^{\text {st }} / 2^{\text {nd }} / 3^{\text {rd }} \\
\text { Pass-band } \\
(\mathrm{GHz})\end{array}$ & $\left|\mathrm{S}_{21}\right|$ in $\mathrm{dB}$ & $\left|\mathrm{S}_{11}\right|$ in dB & FWB (\%) & Application \\
\hline Ref.[1] & $\begin{array}{l}1.8 / 2.7 / \\
3.3-4.8\end{array}$ & $2.2 / 2.1 / 1.3$ & $14 / 13 / 9$ & $3.9 / 2.6 / 40$ & $\begin{array}{l}\text { GSM } \\
\text { WiMAX } \\
\text { UWB }\end{array}$ \\
\hline Ref.[8] & $2.4 / 3.5 / 5.2$ & $0.9 / 1.7 / 2.1$ & $23 / 15 / 13$ & $13.5 / 7 / 3.5$ & $\begin{array}{l}\text { WLAN } \\
\text { WiMAX } \\
\text { WLAN }\end{array}$ \\
\hline Ref.[16] & $\begin{array}{l}2.45 / 3.5 / \\
5.25\end{array}$ & $2 / 2.4 / 1.7$ & $18 / 16 / 13$ & $2.5 / 1.7 / 5$ & $\begin{array}{l}\text { WLAN } \\
\text { WiMAX } \\
\text { WLAN }\end{array}$ \\
\hline Ref.[17] & $2.4 / 3.8 / 5.7$ & $0.8 / 2.0 / 2.5$ & $22 / 18 / 28$ & $7.5 / 3 / 4$ & $\begin{array}{l}\text { WLAN } \\
\text { WiMAX } \\
\text { WLAN }\end{array}$ \\
\hline $\begin{array}{l}\text { Propose } \\
\text { filter }\end{array}$ & $1.8 / 2.86 /$ & $0.98 / 0.28 / 0$ & $10.19 / 26.6$ & $\begin{array}{l}2.24 / 6.96 / \\
43.69\end{array}$ & $\begin{array}{l}\text { GSM } \\
\text { WiMAX } \\
\text { UWB }\end{array}$ \\
\hline
\end{tabular}

The group delay is obtain by the taking the derivative of the phase as depicted in Figure 9 and varies in between $0.21-0.22 \mathrm{~ns}$ at $1.8 \mathrm{GHz}, 6.15-.22 \mathrm{~ns}$ at $2.86 \mathrm{GHz}$ and $0.1-0.13 \mathrm{~ns}$ for $3.32-$ $5.12 \mathrm{GHZ}$. In this filter design the circuit size is very small and tri-band filter with two narrow bands and one UWB filter.

\section{Conclusion}

A triple-band BPF has been design using four asymmetric SIRs and U-shape DGS was proposed for the application of GSM $(1.8 \mathrm{GHz})$, WiMAX $(2.86 \mathrm{GHz})$ and UWB (3.32$5.12 \mathrm{GHz})$. Triple-band response is obtain by intelligently choosing the impedance ratio (R) and length ratio $(\mathrm{u})$ of the asymmetric SIR and the arrangement of the coupling asymmetric SIRs with the U-shape DGS to satisfy required responses for two narrow bands and UWB responses. The Figure 7 shows triple band response, where bandwidth in UWB increases to about $20 \%$. The performance improvement then the others previous work are shown in the table2. The proposed filter demonstrating compact size, low insertion loss and good pass band selectivity.

\section{Acknowledgements}

The authors would like to extend their senior heartiest obligation to the dept. of ECE and CSE, NIT Arunachal Pradesh for his endless support. Also, we would like to thank Prof. (Dr.) C.T.Bhuniya SMIEEE and director of NIT, Arunachal Pradesh, India, for his support to complete our work. And also we would like to thank IC Design and Fabrication centre, Jadavpur University for providing software Facilities to carry out this research work.

\section{References}

[1] Y. C. Chang, C. H. Kao, M. H. Weng and R. Y. Yang, "Design of the compact dual-band bandpass filter with high isolation for GPS/WLAN applications," IEEE Microw. Wireless Compon. Lett., vol. 19, (2009), pp. 780-782. 
[2] Y. S. Lin, C.-C. Liu, K.-M. Li and C.-H. Chen, "Design of an LTCC tri-band transceiver module for GPRS mobile applications," IEEE Trans. Microw. Theory Tech., vol. 52, no. 12, (2004) December, pp. 2718-2724.

[3] W. Y. Chen, M.-H. Weng, S. J. Chang, H. Kuan and Y.-H. Su "A New Tri-Band Bandpass Filter For GSM, WiMAX And UWB Responses By Using Asymmetric Stepped Impedance Resonators", Progress In Electromagnetics Research, vol. 124, (2012), pp. 365-381.

[4] J. S Hong and M. J. Lancaster, "Microstrip Filters for RF/Microwave Applications", New York: Wiley, (2001) July, pp. 153-158.

[5] X. P. Chen, K. Wu and Z. L. Li, "Dual-band and triple-band substrate integrated waveguide filters with chebyshev and quasi- elliptic responses," IEEE Trans. Microw. Theory Tech., vol. 55, (2007), pp. 2569-2578.

[6] W. L. Tsai and R. B. Wu, "Tri-band filter design using substrate integrated waveguide resonators in LTCC," IEEE MTT-S Int. Microw. Symp. Dig., (2011).

[7] W. Y. Chen, M. H. Weng, S. J. Chang and H. Kuan, "A high selectivity dual-band filter using ring-like SIR with embedded coupled open stubs resonators," Journal of Electromagnetic Waves and Applications, vol. 25, No. 14-15, (2011), pp. 2011-2021.

[8] M. H. Weng, C. H. Kao and Y. C. Chang, "A compact dual- band bandpass filter with high band selectivity using cross-coupled asymmetric SIRs for WLANs," Journal of Electromagnetic Waves and Applications, vol. 24, no. 2-3, (2011), pp. 161-168.

[9] V. Ahumada, M. D. C., J. M. Villagr, F. Medina and F. Mesa, "Application of stub loaded folded stepped impedance resonators to dual band filters," Progress In Electromagnetics Research, vol. 102, (2010), pp. 107124.

[10] X. Lai, N. Wang, B. Wu and C.-H. Liang, "Design of dual-band filter based on OLRR and DSIR," Journal of Electromagnetic Waves and Applications, vol. 24, no. 2-3, (2010), pp. 209-218.

[11] S. Luo, L. Zhu and S. Sun, "Compact dual-mode triple-band bandpass filters using three pairs of degenerate modes in a ring resonator," IEEE Trans. Microw. Theory Tech., vol. 59, (2011), pp. 1222- 1229.

[12] X. Lai, C. H. Liang, H. Di and B. Wu, "Design of tri-band filter based on stub loaded resonator and DGS resonator," IEEE Microw. Wireless Compon. Lett., vol. 20, (2010), pp. 265-267.

[13] Y. Liu, W.-B. Dou and Y.-J. Zhao, "A tri-band bandpass filter realized using tri-mode T-shape branches," Progress in Electromagnetics Research, vol. 105, (2010), pp. 425-444.

[14] C. H. Lee, C. I. G. Hsu and H. K. Jhuang, "Design of a new tri-band microstrip BPF using combined quarterwavelength SIRs," IEEE Microw. Wireless Compon. Lett., vol. 16, (2006), pp. 594-596.

[15] C. I. G. Hsu, C. H. Lee and Y. H. Hsieh, "Tri-band bandpass filter with sharp pass band skirts designed using tri-section SIRs," IEEE Microw. Wireless Compon. Lett, vol. 18, (2008), pp. 19-21.

[16] S.-G. Mo, Z.-Y. Yu and L. Zhang, "Design of triple- mode bandpass filter using improved hexagonal loop resonator," Progress In Electromagnetics Research, vol. 96, (2009), pp. 117-125.

[17] L. Zhang, Z. Y. Yu and S. G. Mo, "Novel planar multimode bandpass filters with radial-line stubs," Progress In Electromagnetics Research, vol. 101, (2010), pp. 33-42.

[18] Y. C. Chiou and J. T. Kuo, "Planar multiband bandpass filter with multimode stepped-impedance resonators," Progress In Electromagnetics Researc, vol. 114, (2011), pp. 129-144.

[19] F. C. Chen and Q. X. Chu, "Design of compact tri-band bandpass filters using assembled resonators," IEEE Trans. Microw. Theory Tech., vol. 57, (2009), pp. 165-171.

[20] X. Guan, Z. Ma and P. Cai, "A novel triple-band microstrip bandpass filter for wireless communication," Microw. Opt. Tech. Lett., vol. 51, (2009), pp. 1568-1569.

[21] L. Zhu, H. Bu and K. Wu, "Aperture compensation technique for innovative design of ultra-broadband microstrip bandpass filter,” IEEE MTT-S Int. Microw. Symp. Dig., (2000).

[22] N. Thomson and J. S. Hong, "Compact ultra-wideband microstrip/coplanar waveguide bandpass filter," IEEE Microw. Wireless Compon. Lett. vol. 17, (2007), pp. 184-186.

[23] W. Y. Chen, Y. H. Su, H. Kuan and S. J. Chang, "Simple method to design a tri-band bandpass filter using asymmetric SIRs for GSM, WiMAX, and WLAN applications,” Microw. Opt. Tech. Lett., vol. 53, (2011), pp. $1573-1576$.

[24] J. P. Hu, G. H. Li, H. P. Hu and H. Zang, "A new wideband triple-band filter using SIR," Journal of Electromagnetic Waves and Applications, vol. 25, no. 16, (2011), pp. 2287-2295.

[25] R. Li and L. Zhu, "Compact UWB bandpass filter using stub-loaded multiple-mode resonator," IEEE Microw. Wireless Compon. Lett., vol. 17, (2007), pp. 40-42.

[26] C. Y. Liu, T. Jiang and Y.-S. Li, "A novel UWB filter with notch-band characteristic using radial-UIR/SIR loaded stub resonators," Journal of Electromagnetic Waves and Applications, vol. 25, no. 2-3, (2011), pp. 233-245.

[27] F. Wei, L. Chen, Q. Y. Wu, X. W. Shi and C. J. Gao, "Compact UWB bandpass filter with narrow notch-band and wide stop-band," Journal of Electromagnetic Waves and Applications, vol. 24, no. 7, (2010), pp. 911-920.

[28] J. Cu, B. Li, H. Wang, C. Miao and W. Wu, "Compact UWB bandpass filter with multiple ultra-narrow notched bands," Journal of Electromagnetic Waves and Applications, vol. 25, no. 7, (2011), pp. 987-998. 
[29] S. Fallahzadeh and M. Tayarani, "New microstrip UWB bandpass filter using defected microstrip structures," Journal of Electromagnetic Waves and Applications, vol. 24, no. 7, (2010), pp. 893-902.

[30] Y. C. Chang, C. H. Kao, M. H. Weng and R. Y. Yang, "Design of the compact wideband bandpass filter with low loss, high selectivity and wide stopband," IEEE Microw. Wireless Compon. Lett., vol. 18, (2008), pp. 770-772.

[31] D. L. Kaczman, M. Shah, N. Godambe, M. Alam, H. Guimaraes, L. M. Han, M. Rachedine, D. L. Cashen, W. E. Getka, C. Dozier, W. P. Shep- herd and K. Couglar, "A single-chip tri-band (2100, 1900, 850/800 MHz) WCDMA/HSDPA cellular transceiver," J. Solid-State Circuits, vol. 41, no. 5, (2006) May, pp. 1122-1132.

[32] D. Ahn, J. S. Park, C. S. Kim, J. Kim, Y. Qian and T. Itoh, "A design of the low-pass filter using the novel microstrip defected ground structure," IEEE Microw. Theory Tech., vol. 49, (2001), pp. 86-93.

[33] "Federal Communications Commission", Revision of Part 15 of the Commission's Rules Regarding UltraWideband Transmission Systems FCC, Tech. Rep., ET-Docket FCC02-48, (2002) February, pp. 98-153.

[34] T. A. Sheikh, J. Borah and S. Roy, "Bandwidth improvement in BPF using microstrip couple lines", ICSSP'14, proceeding of Int. Conf. on Signal and Speech Processing'14, Elsevier publisher, (2014) August 21-23, Kerela, India.

[35] T. A. Sheikh, J. Borah, S. Roy and A. K. Pandey, “ A New Compact Dual Band Microstrip BPF For GSM1800 And WiMAX Using Asymmetric Stepped Impedance Resonators”, Proceeding of Int. Conf. on Recent Cognizance in Wireless Communication and Image Processing'2014, Springer Publication, (2015) January 16-17, Jaipur, India.

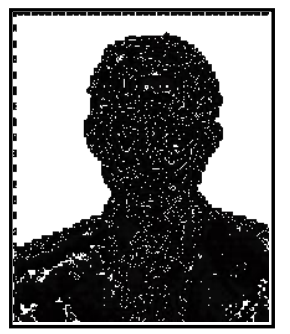

Tasher Ali Sheikh received his B.Tech degree in Electronics and Communication Engineering from Central Institute of Technology (CIT), Kokrajhar, India in 2013. He has undertaken various microstrip filter based projects. His field of interest includes DSP, Microwave Filter design for RF communication, Microwave antenna design and Mobile Communication. He enrolled for the Master of Technology in "Mobile Communication and Computing" at National Institute of Technology (NIT), Arunachal Pradesh, India in the month August, 2013. He has published some research paper in Book Chapter, Conference and international journals.

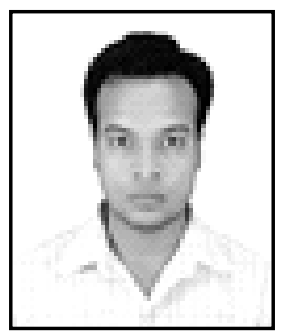

Janmoni Borah received his B.Tech degree in Electronics and Communication Engineering from Central Institute of Technology, Kokrajhar, India in 2013. He is currently pursuing M.Tech in Mobile Communication and Computing at National Institute of Technology, Arunachal Pradesh, India. His research interest includes Mobile communication, Microstrip antenna design for multi-band applications, Microstrip filter design and Green computing. He has published some research papers in International journals and conferences. 


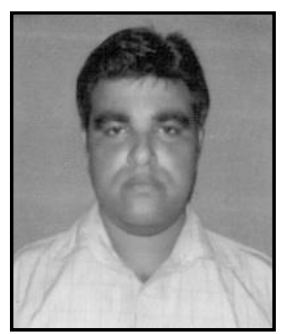

Sahadev Roy Author's is currently working as an Assistant Professor in the Department of Electronics \& Communication Engineering at NIT, Arunachal Pradesh, India. He has more than 10 years of experience in research and teaching field. He received his B.Tech degree in ECE and M.Tech, in Mechatronics from Bengal Engineering and Science University, Shibpur, India. He is pursuing PhD in VLSI from NIT, AP. $\mathrm{He}$ has published a number of scientific papers in National and International Journals. His research interest includes Robotics, Microwave and VLSI design. 